Arteterapia. Papeles de arteterapia y educación para inclusión social ISSN: $1886-6190$

\title{
Las cinco fases de la intervención psicoterapéutica frente al trauma
}

\author{
Jorge Marugán Kraus ${ }^{1}$
}

Recibido: 16 de junio de 2016 / Aceptado: 26 de septiembre de 2016

Resumen. Este trabajo plantea un modelo de intervención psicoterapéutica frente al trauma psicológico y el dolor que éste provoca en el espacio límite entre lo psíquico y lo somático tomando la referencia de un testimonio recogido en el film Shoah de Claude Lanzmann. Se analizan las diferentes temporalidades en la manifestación de lo traumático, se cuestiona la posibilidad de convertir el trauma en acontecimiento historizado y se determinan las funciones del psicoterapeuta en cada una de las fases del proceso de elaboración.

Palabras clave: trauma; dolor; psicoterapia; transferencia.

\section{[en] The five phases of psychotherapeutic intervention against trauma}

Abstract. This paper presents a model of psychotherapeutic intervention against psychological trauma and pain that this causes in the boundary area between the psychic and somatic, taking the reference from a testimony taken in the film Shoah Claude Lanzmann. Different time frames are analyzed in the manifestation of trauma, the possibility of converting the trauma in an historical event is questioned and the psycotherapist functions in each of the phases of the process are determined.

Keywords: trauma; pain; psychotherapy; transference.

Sumario. 1. Trauma psicológico frente a acontecimiento historizado; 2. Trauma, duelo y repetición; 3. Psicoterapia del trauma en cinco tiempos; 4. Referencias bibliográficas.

Cómo citar: Marugán Kraus, J. (2016) Las cinco fases de la intervención psicoterapéutica frente al trauma, en Arteterapia. Papeles de arteterapia y educación para inclusión social 11, 343-353.

\section{Trauma psicológico frente a acontecimiento historizado}

Guerras, asesinatos, agresiones, accidentes, abandonos, abusos, desamparo, fallecimiento de seres amados, amenazas, humillaciones, mutilaciones, coacciones... más allá de los sucesos y las crisis inevitables en el proceso vital de cada ser hu-

1 Departamento de Psicología Evolutiva y de la Educación. Universidad Complutense de Madrid. . Psicólogo Especialista en Psicología Clínica. Profesor del Máster Oficial en Arte-terapia y Educación Artística para la Inclusión Social y del Máster Oficial en Psicoanálisis y Teoría de la Cultura (U.C.M)

E-mail: jmarugank@yahoo.es 
mano, el acontecer puede golpear con una violencia de consecuencias trágicas, irreparables para el sujeto.

Para una primera aproximación al concepto de trauma psicológico podemos imaginar el impacto que causaría un gran asteroide que chocara sobre la superficie de un pequeño planeta: el asteroide abriría un gran cráter alterando el equilibrio geológico del planeta y su morfología, podría llegar incluso a abrirse paso hasta su núcleo, fundirse en él y alterar su composición. Si imaginamos, además, que el brutal impacto cambiaría también el movimiento orbital de ese planeta tendríamos una idea inicial de lo que el trauma psicológico puede ocasionar.

El trauma psicológico provoca una disfunción del sujeto, no solo cuantitativa, entendiendo lo cuantitativo como cantidades de energía no procesables o tramitables por el aparato psíquico, sino también una alteración cualitativa, la imposición de una nueva subjetividad. Después del trauma el sujeto sentirá, pensará o se expresará de otra manera. Es decir, después del trauma surgirá un nuevo sujeto.

Tomemos un ejemplo real, un testimonio estremecedor de la maldad humana. Lo transcribimos parcialmente del documento cinematográfico titulado Shoah, dirigido por Claude Lanzmann y estrenado en 1985. Son fragmentos de la entrevista realizada por el propio director al peluquero judío Abraham Bomba, mientras este trabaja en su propia peluquería. Abraham es superviviente del campo de exterminio de nazi de Treblinka:

'Peluqueros, debéis proceder de tal modo, que todas las mujeres que entren aquí, crean que, simplemente, van a tener un corte de pelo, tomar una ducha

y que en seguida saldrán'.

Pero sabíamos ya, que de este lugar no se salía, que era el último, que no saldrían vivas

[...]

Nosotros, los peluqueros, comenzábamos a cortar el pelo

y algunas, debería decir casi todas, saben ya

lo que les va a pasar.

Nosotros intentamos hacer lo mejor...

Ser lo más humanos posible

[...]

Entraban desvestidas, totalmente desnudas, sin ropa, sin nada. Todas las mujeres y todos los niños

[...]

Obedecía órdenes: cortar el pelo

como lo habría hecho un peluquero

que hace un corte normal,

pero que al mismo tiempo debe apurar al máximo.

Porque ellos necesitaban el pelo de las mujeres, que expedían a Alemania

[...]

Los alemanes querían sus cabellos, ellos tenían sus razones. 
$[\ldots]$

¿"Sentir" ahí abajo?

Era muy duro tener cualquier sentimiento.

Imagínese trabajar día y noche entre los muertos, los cadáveres,

Los sentimientos de uno desaparecían,

Uno estaba muerto al sentimiento, muerto a todo.

[Hasta este momento, Abraham articula su discurso como un robot, como un reproductor de audio, desconectado afectivamente de sus propias palabras]

Le voy a contar una cosa:

Durante el periodo en que fui peluquero en la cámara de gas,

llegaron algunas mujeres de un transporte que procedía

de mi ciudad, Czestochova.

Conocía a un gran número de ellas.

Sí yo las conocía, vivía en la misma ciudad.

Vivía en la misma calle.

Algunas eran amigas cercanas.

$Y$ desde que me vieron todas se agarraron a mí.

"Abe, ¿qué haces tú aquí? ¿qué es lo que nos van a hacer?”

¿qué podías tú decirles? ¿qué podías tú decirles?

Un amigo mío estaba conmigo,

era también un buen peluquero en mi ciudad.

Cuando su mujer y su hermana fueron

introducidas en la cámara de gas...

[Abraham calla por pura asfixia, aunque sigue cortando mecánicamente el pelo de su cliente. Pasados unos minutos de terrible silencio agónico abandona su tarea y articula:]

Es demasiado horrible...

Sería incapaz.

No prolongue esto...

Ya se lo he dicho, esto será muy duro...

[De nuevo el silencio, que rompe con un murmuro casi inaudible en yiddish, su lengua natal:]

Ellos metían esto en sacos y

era enviado a Alemania.

[Señala los manojos de pelo cortado. Después, ante la insistencia inflexible del director Lanzmann, Abraham continúa:]

...Trataba de hablarles, pero tanto a una

como a la otra

era imposible decirles que se trataba del último instante 
de su vida, porque detrás estaban los nazis, los SS, y sabía que si decía una sola palabra compartiría la suerte de esas dos mujeres que eran ya como muertos.

Pero sin embargo, hacía por ellas lo máximo, quedarse con ellas un segundo más, un minuto más, las estrechaba, las abrazaba.

Porque sabía que no las volvería a ver jamás.

¿Cómo rescatar desde la psicología clínica algo de lo humano, de la palabra, del sentido, después de este impacto, de este encuentro con la maldad y la locura? ¿Cómo seguir viviendo después de esto?

Establezcamos algunas consideraciones sobre el trauma psicológico a partir de nuestra escucha clínica:

$1^{\circ}$. El trauma psicológico tiene un efecto de destitución subjetiva, de suspensión de la afectividad, e incluso de la identidad del sujeto, un efecto de colapso en sus funciones:

- cortar el pelo como lo habría hecho un peluquero... ['como un peluquero' implica que en ese momento Abraham no se sentía como tal]

- '¿sentir?... uno estaba muerto al sentimiento, muerto a todo'.

El efecto de destitución subjetiva permite, paradójicamente, defender al ser frente al trauma, preservar la supervivencia individual sacrificando una parte de la propia vida; como los lagartos que separan su cola ante el peligro. Esto explica, por ejemplo, algunos testimonios de víctimas que pueden ir acompañados de una intensa culpabilidad: ¿por qué no grité? ¿por qué no luché?

$2^{\circ}$. Los efectos del impacto traumático no se pueden predeterminar. Una misma situación produce consecuencias diferentes en sujetos diferentes, e incluso en momentos diferentes de la vida de un mismo sujeto. No convendría, por tanto, diseñar modelos de intervención terapéutica rígidos o preestablecidos, cada sujeto precisa su propio tiempo de elaboración.

$3^{\circ}$. El dolor es una manifestación en el límite entre lo físico y lo psíquico, implica ambos registros diluyendo sus fronteras.

$4^{\circ}$. La huella traumática hunde sus raíces en el aparato psíquico produciendo manifestaciones de angustia ante situaciones que pueden no estar directamente asociadas al trauma y que se imponen repetitivamente: sueños, pensamientos, acciones, temores, agitación...

$5^{\circ}$. Hay una parte elaborable del trauma, una parte que se puede tramitar subjetivamente. El sujeto puede incorporar parcialmente la huella traumática a su propia historia. Para ello tendrá que hacer de esa huella una marca legible, interpretable, significable desde la palabra y el lenguaje.

$6^{\circ}$. Igualmente, una parte del trauma se mantiene como tal, persiste como un agujero más allá de la palabra y el sentido; más allá de la posibilidad de transcribir completamente la marca dejada en el plano del lenguaje. 
Con todo, a partir del impacto dejado por la contingencia traumática, proponemos hacer la siguiente diferenciación:

- Llamar 'acontecimiento' a la contingencia traumática que ha podido ser leída e historizada por el sujeto, a pesar de su carácter inesperado y diferente del curso uniforme de sucesos. El acontecimiento será siempre un acontecimiento del decir y conllevará la emergencia de un sujeto implicado afectivamente en su propia palabra.

- El término 'trauma' nombraría entonces lo que de esa contingencia quedaría como estrictamente real y sin sentido, como agujero no significado en la historia del sujeto.

\section{Trauma, duelo y repetición}

El trauma persistiría, entonces, como un agujero que no puede cerrarse, que hará fracasar los recursos lingüísticos del sujeto y que va a concentrar y a atraer hacia sí grandes cantidades de energía manifestada en forma de angustia que condiciona la dinámica del aparato psíquico. El trauma conllevará, por tanto, una nueva organización subjetiva.

Cuando escuchamos el relato del suceso traumático debemos tener en cuenta que la memoria tiende a traicionarnos. Ya desde 1898 Sigmund Freud (1996b y 1996c) estableció la función encubridora de los recuerdos y el carácter selectivo de los olvidos ante la amenaza del dolor no rememorable. Este autor encontrará en su clínica una manifestación más fiable del trauma: la repetición (Freud, 1996d, 152): 'El analizado no recuerda, en general, nada de lo olvidado y reprimido, sino que lo actúa $[\ldots]$ repite en vez de recordar'.

Pero, ¿por qué el trauma se manifiesta como compulsión repetitiva de manifestaciones que conllevan dolor o angustia?, ¿por qué regresa el recuerdo doloroso en sueños o síntomas o, incluso, se tiende a emular o repetir situaciones que recuerdan al trauma?

Podemos intentar una respuesta: tales repeticiones intentan asegurar los límites de ese agujero, intentan que el vacío que conlleva no se desborde y su apertura crezca; para ello el sujeto tiende a recordar, a intensificar, a reinvestir de energía psíquica sus bordes, sus marcas. El sujeto repite las representaciones dolorosas que hacen de ese vacío un agujero, que limitan el vacío y que, a la vez, lo localizan y lo contienen.

Ante esta situación podemos establecer dos objetivos de la psicoterapia:

$1^{\circ}$. Transformar, en la medida de lo posible, el trauma en acontecimiento.

$2^{\circ}$. Hacer de ese exceso que sobrepasa al sujeto y que este no puede incorporar, de ese agujero o resto traumático no historizado, un objeto manejable y compatible con la propia consistencia del sujeto.

Respecto a la manifestación repetitiva del trauma, la clínica nos muestra una diferencia fundamental que establece dos tipos diferentes de repeticiones, en función de si lo que se repite es 'presentación' o 're-presentación':

$1^{\circ}$. La repetición de lo que se 're-presenta' implica un intento de escribir el trauma en la historia del sujeto. Se repiten elementos que intentan significar, escenificar, simbolizar, dar sentido al trauma. Son repeticiones que abren 
interrogantes, que tienden a ir modificándose, afectadas por el tiempo o el proceso terapéutico. Estos elementos conllevan una elaboración, son productos de un trabajo psíquico en el intento de transformar el trauma en acontecimiento. Las representaciones de lo traumático que insisten, que se repiten, sorprenden fugazmente y cuestionan al sujeto. Se manifiestan, por ejemplo, en un sueño, un lapsus, el efecto inesperado de un síntoma o, como le sucede a Abraham, una manifestación repentina de dolor punzante.

$2^{\circ}$. La repetición de lo que, sencillamente, se 'presenta'. Lo que se presenta se repite como idéntico, sin cambio ni elaboración. Son manifestaciones que no apuntan al sentido, más bien al eco de ese núcleo traumático no asimilable. Se trata de elementos que no cambian, que se repiten cada vez como la primera vez. Por ejemplo, una determina acción compulsiva que adquiere, incluso, carácter adictivo; o la repetición de un testimonio sin implicación afectiva, como inicialmente en el caso de Abraham; o la manifestación de algunos síntomas y fantasías que no presentan una intención de significación, que no sorprenden $\mathrm{y}$, por tanto, no cuestionan nada del sujeto; restos del trauma que tienden a permanecer y repetirse.

Presentaciones y representaciones implican diferentes temporalidades que la psicoterapia debe contemplar: tendrá que introducir la espera para soportar la repetición de lo que se 'presenta'. Y solo a partir de la espera se posibilita la sorpresa capaz de interrumpir esa repetición; al igual que la escucha sólo es posible a partir del silencio. La psicoterapia anuda repetición y sorpresa, presentación y representación.

\section{Psicoterapia del trauma en cinco tiempos}

¿Cómo puede la psicoterapia cambiar el pasado? ¿qué recursos tenemos para elaborar el impacto traumático interviniendo desde el presente sobre algo que pudo suceder hace mucho tiempo? Freud introduce aquí un concepto fundamental, presente en toda su obra: la retroactividad ('nachträglich') en la estructuración del psiquismo. La retroactividad viene a cuestionar el concepto de evolución en el desarrollo de lo humano; plantea la acción retardada de ciertos sucesos que sólo tendrán su manifestación efectiva 'a posteriori', una vez que se han producido ciertos cambios que alteran las huellas que tales sucesos han dejado. Esos cambios, por tanto, alteran el pasado desde el futuro, tendrán un efecto retroactivo, de delante a atrás, en la historia subjetiva. Freud (1996a, p. 167) considera que la madurez sexual de la pubertad, por ejemplo, reactiva desde el futuro el efecto traumático de un abuso sexual acaecido en la infancia al aumentarse las inervaciones genitales del púber. Este principio de retroactividad en el desarrollo permite legitimar el efecto terapéutico de la palabra sobre la elaboración del trauma siempre que se den ciertas condiciones.

Pero, ¿cómo se establece el efecto retroactivo de la psicoterapia sobre el trauma?, ¿qué condiciones se requieren?, ¿cómo hacemos del trauma acontecimiento?

Articulemos la intervención psicoterapéutica sobre el trauma en cinco tiempos sucesivos, tomando como referencia el testimonio de Abraham Bomba en Shoah. 


\section{Primer tiempo: impacto y destitución subjetiva}

Fijemos el punto de partida: el momento del impacto que conlleva una destitución de las funciones subjetivas:

\section{'- ¿sentir?... estaba muerto al sentimiento'.}

Y Abraham sigue, en parte, muerto. Puede hablar con detalle de lo que sucedió, no lo ha olvidado, pero habla sin implicación, sin emoción. Podría repetir el relato mil veces y nada cambiaría. En este caso la defensa frente al dolor no es tanto por represión y olvido, sino a través de una destitución afectiva, un aislamiento emocional. Esta posición frente al dolor ocupa la mayor parte de su testimonio, se da en la primera parte de la entrevista, pero también resurge al final. Abraham elude el encuentro con los bordes del agujero, con las marcas que ha dejado en su 'cuerpo doliente' ese suceso. Abraham podría ser también, en este momento, un sujeto 'colmado de dolor', de dolor sin bordes, donde todo él es dolor. Como si estuviera completamente absorbido por ese agujero traumático: despedazado, desubjetivado, caído, vacío.

¿Qué lugar, qué acción le corresponde al psicoterapeuta en este primer tiempo? Podríamos responder que ninguna porque, simplemente, no hay lugar para él. La destitución subjetiva producida por el impacto no deja lugar al otro, al vínculo terapéutico. En este primer tiempo el terapeuta no tiene presencia terapéutica. Quizá es uno de los momentos más desoladores y difíciles de soportar para el propio psicoterapeuta: ocupar un lugar en el que no hay lugar.

\section{Segundo tiempo: el atravesamiento del dolor.}

De repente, surge en Abraham de forma inesperada, no predeterminada, un ahogo, una asfixia; la emergencia de un dolor punzante que se atraviesa y detiene su discurso vacío. Adviene entonces un silencio agónico que dura unos escasos pero interminables minutos. Abraham quiere hablar pero no puede. En el momento álgido interrumpe también el automatismo de la tarea que está realizando. El director insiste rayando en la crueldad:

-Continúe... Debe continuar... Usted lo sabe...

Abraham se defiende:

-Es demasiado horrible... Sería incapaz... No prolongue esto...

Dolor atravesado como un hueso en la garganta, dolor ahogado, silencio, sujeto despojado de la palabra.

Podemos tomar con Lacan (1965) otro ejemplo para este momento: el famoso cuadro titulado El grito, de Edvard Münch. La angustia que esa obra transmite deviene de representar el grito como ahogado, silenciado, como lo muestra el hecho de que otros seres que se difuminan al fondo parezcan caminar ajenos a él. También presenta a un sujeto deshumanizado, más bien una mancha humanoide, sin rasgos, sin oídos para oír su propio grito.

Pese a todo, este atravesamiento del dolor permite una localización muy precaria de ese dolor. No se trata del sujeto todo-dolor, dolor pleno e indiferenciado de la fase anterior. Ahora el dolor ahoga la garganta como un hueso; se trata del dolor como objeto parcial, localizado, incrustado; lo que abre la posibilidad de operar con él.

Además, el dolor atravesado es una precaria expresión de dolor. Y cuando uno 
expresa, expresa para otro. Aunque en este caso solo sea una expresión que muestra, precisamente, aquello que no se puede expresar, abre, sin embargo, la posibilidad de un lugar receptor de nuestra expresión. La distinción de ese lugar receptor permite romper el aislamiento, la soledad del sujeto en su dolor. Resulta ejemplar en el documento de Lanzmann el hecho de que Abraham, pese a contar terribles experiencias propias, sólo puede convertir su dolor en un dolor atravesado cuando habla de su amigo, es decir, cuando puede encontrar ese punto de separación, de ubicación de un lugar-otro en la plenitud de su dolor. Sólo en ese momento su palabra alcanza otra dimensión, se quiebra, a través de la identificación con su amigo. Antes de eso Abraham era sólo pura soledad, palabra vana, testimonio sin sujeto.

Por todo ello, en esta fase emerge el lugar del psicoterapeuta. Él no es ajeno a la producción de la expresión de dolor como objeto atravesado; la posibilita con su presencia haciendo eco de ese silencio. ¿Cuál es, entonces, la función del psicoterapeuta aquí? Soportar su propia angustia, esperar, acompañar, dar tiempo...

Sin embargo, en la escena documental Lanzmann no puede esperar, él no es psicoterapeuta ni pretende serlo. Apela a la importancia de hacer llegar el testimonio de Abraham al mundo y lo fuerza a hablar.

\section{Tercer tiempo: la extracción del dolor.}

Sólo cuando el atravesamiento, el ahogo, llega a su punto límite, el dolor, convertido en objeto asfixiante, se expulsa y surge el grito audible, el llanto o el lamento parcialmente desarticulado. La expresión de dolor, entonces, se materializa y puede ser escuchada aún antes de portar sentido. Toma así una forma de llamada, de demanda dirigida a alguien y conlleva, por tanto, la posibilidad de establecer un vínculo.

Abraham, al límite del ahogo, murmura unas palabras casi inaudibles y casi despojadas de significado. No se las dirige a Lanzmann, que lo entrevista en inglés, ni a ese mundo que supuestamente espera su testimonio sobre los asesinatos. Las palabras emergen en su primitiva lengua materna, murmura algo sobre el pelo cortado que los nazis transportaban a Alemania.

La función del psicoterapeuta aquí se sostiene en la escucha y el silencio. Su presencia requiere dar consistencia y límite a la llamada desesperada, a esa demanda desarticulada y naciente del sujeto.

Muchos psicoterapeutas utilizan indiscriminadamente técnicas que corresponden exclusivamente a esta fase. Lo que llamamos 'técnicas de apoyo, refuerzo y contención' que podrían incluir frases como 'sé que es muy duro...' empleada por el propio Lanzmann, o incluso inducir relajación, consejos positivos, etc. Este tipo de intervenciones pueden ser útiles en este momento para reafirmar la escucha, pero son inútiles o contraproducentes en el resto de las fases.

\section{Cuarto tiempo: articulación del discurso y velamiento del dolor con la imagen del psicoterapeuta.}

Se establece cuando el dolor condensado en grito, llanto o lamento, toma progresivamente la forma de discurso articulado. El sujeto comienza a hablar, pero su palabra no suena hueca o vacía como podía suceder en la fase inicial. Se trata de una palabra en la que el propio sujeto está implicado, representado ante ese agujero 
dejado por el impacto traumático. Agujero que ahora bordea.

Esta fase puede alargarse mucho en un tratamiento y tendrá características y consecuencias importantes. Conllevará el surgimiento de un sujeto en el que el dolor irá dejando progresivamente lugar al deseo. Primero, deseo de hablar, de buscar sentidos.

Segundo, deseo de establecer un vínculo, una relación que canalizará el dolor extraído. Debemos tener en cuenta que en la fase de extracción, el dolor como objeto queda libre, y que se trata de un objeto muy cargado de energía afectiva. Esto confiere a la presencia del psicoterapeuta la función de recepción de ese objeto sobre sí. El objeto liberado en forma de energía afectiva inviste al psicoterapeuta, sobre todo, en el plano imaginario; su imagen podrá resultar muy idealizada o sexualizada. Esta sorprendente 'transferencia' puede potenciar extraordinariamente la posición terapéutica del psicoterapeuta, pero también lo confronta con su ética profesional para no abusar de ese poder.

El dolor extraído, entonces, no desaparece sin más, queda transferido al vínculo terapéutico y velado por la imagen del psicoterapeuta que será objeto de todo tipo de fantasías. La fijación del sujeto a estas fantasías manifiestan, de nuevo, el mecanismo de repetición del trauma y pueden bloquear su elaboración (Freud, 1996e, p. 165). Se produce así la paradoja de que cuanto más deseo se manifieste de articular el dolor en el discurso, más se vela este dolor y más se fija a la fantasía producida.

La experiencia clínica nos muestra frecuentemente cómo el deseo del sujeto queda bloqueado por una fijación fantasmática a la imagen del psicoterapeuta. Para el psicoanalista Jacques-Allain Miller (1992, p. 20) obtener la revelación de esas fantasías y cuestionarlas es una parte del trabajo terapéutico; la resistencia a comunicarlas no es sólo por vergüenza, sino también porque tapan y remiten a ese agujero innombrable que las causó: 'la angustia misma aparece cuando hay un desfallecimiento de la cobertura fantasmática'. Las fantasías pueden manifestarse como repetición compulsiva, sin enigma, y la labor de cuestionarlas requerirá el correspondiente manejo de los tiempos subjetivos.

Creemos, en nuestro ejemplo, que Abraham no alcanza esta fase de articulación y velamiento transferencial del dolor como objeto. Hay atravesamiento, y un atisbo de extracción, pero la insistencia de Lanzmann fuerza y precipita un regreso a la fase de impacto y destitución subjetiva. Abraham sigue hablando, sí, pero su palabra vuelve a no representarlo frente al dolor, vuelve al automatismo, a su soledad plena de dolor.

En general, la intervención del psicoterapeuta en esta fase se caracteriza por facilitar la articulación de un discurso que genere efectos de sentido: podrá ordenar y puntuar el discurso del sujeto, clarificar aspectos oscuros, confrontarlo con ciertas consecuencias de sus actos, señalar y separar lo importante de lo accesorio, establecer relaciones entre unos temas y otros... Si, en este momento, la función terapéutica se sostiene y potencia por la atribución de saber que el sujeto le otorga, el terapeuta tendrá que soportar esa suposición de saber, pero no identificarse con ella porque el saber está siempre del lado del sujeto. El terapeuta dará soporte a un saber, que en el fondo tiene poco que ver con él, desde la ética de la abstinencia. Simplemente escenificará la idealización del objeto velado, verdadero causante de esta relación transferencial. El encuentro con sentidos nuevos, esclarecimientos, 
descubrimientos o 'insight' a partir de un saber supuesto o atribuido son descriptores típicos de esta fase.

\section{Quinto tiempo: acto de corte, caída y reintroducción del dolor como objeto velado.}

La fase anterior tiene el riesgo de convertirse en un idilio perpetuo entre el psicoterapeuta y su paciente enquistando la terapia. Si la psicoterapia introduce la espera para posibilitar la sorpresa que rompa la repetición, este quinto tiempo es, precisamente, el tiempo de la sorpresa. Se trata, por fin, del derrumbe del escenario fantasmático transferencial y el desvelamiento necesario del dolor.

El psicoterapeuta tendrá que efectuar una ruptura del discurso articulado alrededor del sentido y el saber a través de otra modalidad de intervención: el corte en acto. Acto porque tiene más que ver con un 'hacer' del terapeuta que con un decir y que muestra que su función es activa, que no se debe confundir abstinencia y pasividad. Un acto que manifiesta un deseo decidido por parte del terapeuta de cortar el discurso que perpetúa lo imaginario; acto arriesgado porque franquea un limite, más allá del sentido y del cálculo. Debemos la instauración de esta técnica a la aportación de Jacques Lacan (1999, p. 565).

¿Cómo adviene este acto de corte del discurso que hace caer el objeto velado por la transferencia? Hay dos vías posibles que se pueden combinar y complementar:

$1^{\circ}$. La intervención del psicoterapeuta basada en el sinsentido, la extrañeza o el equívoco. Intervención que no instaura un saber sino que introduce un enigma, una suspensión del sentido en el discurso del paciente y cuestiona toda suposición previa de saber. Resulta difícil ejemplificarlo porque el efecto de ruptura depende del momento y la singularidad de cada caso y no puede entenderse simplemente por el dicho en sí que lo provoca, y menos por su sentido aparente. En el discurso de un paciente, por ejemplo, cuando se refería a sus amigos utilizaba cada vez la fórmula: 'mi amigo Pepe (o Juan o el que fuera)... ', es decir, reafirmaba la condición de amistad cada vez, a pesar de ser suficientemente conocida esa relación por el terapeuta. Una intervención del tipo: -siempre repite "mi amigo...", puede provocar el efecto de ruptura, constituiría un decir con la dimensión de un acto. $\mathrm{O}$ ante el relato de una mujer que cuenta las discusiones, enfados y castigos que se suceden en la relación con su hijo de 10 años y que consumen todo su tiempo, surge: 'parece una discusión de novios'. Este tipo de intervenciones no se preparan, no se piensan, no funcionan por su sentido obvio, a veces una tos o un gesto del terapeuta (por ejemplo un atisbo de bostezo o de sonrisa) tienen ese mismo efecto. No se pueden anticipar, se detectan porque también en el propio terapeuta retumba esa caída del escenario y porque darán paso a un nuevo proceso de elaboración.

$2^{\circ}$. Una intervención en la que se realiza el corte efectivo e inesperado de la sesión de trabajo con el paciente. Acto de corte que interrumpe el discurso del sujeto en la sesión que en ese momento está basado en la inmediatez y lo suspende abriendo un tiempo de elaboración fuera de ella, posponiendo la resolución del enigma planteado.

La efectividad de estos tipos de intervención se sostienen en que se haya establecido previamente la relación transferencial aludida en la fase anterior, si no 
es así pueden volverse contraproducentes por la dificultad de elaborar en el espacio terapéutico la angustia que pueden generar.

El acto de corte del psicoterapeuta en condiciones adecuadas supone la interrupción de la repetición de las fantasías que bloquean el deseo del sujeto y su reactivación para que ese deseo se ponga en juego en la vida del paciente. Hay que señalar que el acto de corte no entra en el registro de las gratificaciones o las respuestas a la demanda que el paciente pueda hacer al terapeuta, o este al paciente. Se trata de un acto separador, con la frustración que conlleva. El psicoterapeuta escenifica ahora al objeto que cae, es imprescindible que no se coloque en posición de 'amo' del sentido, sino en posición de objeto perdido, cortado, vacío para la transferencia.

El acto de corte conlleva una caída y un desvelamiento del dolor, un nuevo impacto que reintroduce el dolor y la angustia en el sujeto. Resulta llamativo que esta 'inoculación' de una porción de angustia responda al mismo principio que las vacunas: se ataca al virus introduciendo una porción del mismo virus.

Finalmente, el sujeto será confrontado a reencontrarse con ese agujero traumático y a reiniciar las fases del proceso. El modelo propuesto adquirirá entonces un funcionamiento circular, las mismas fases podrán sucederse muchas veces: renovación del sentido, reelaboración, resignificación, reapuntalamiento de los bordes que contienen y limitan un agujero que puede reducirse, pero nunca cerrarse completamente.

\section{Referencias bibliográficas}

Freud, S. (1996a). Nuevas puntualizaciones sobre las neuropsicosis de defensa. En Obras Completas, vol. 3 (pp. 157-184). Buenos Aires, Argentina: Amorrortu.

Freud, S. (1996b). Sobre el mecanismo psíquico de la desmemoria. En Obras Completas, vol. 3 (pp. 277-290). Buenos Aires, Argentina: Amorrortu.

Freud, S. (1996c). Sobre los recuerdos encubridores. En Obras Completas, vol. 3 (pp. 291316). Buenos Aires, Argentina: Amorrortu.

Freud, S. (1996d). Recordar, repetir, reelaborar. En Obras Completas, vol. 12 (pp. 145158). Buenos Aires, Argentina: Amorrortu.

Freud, S. (1996e). Puntualizaciones sobre el amor de transferencia. En Obras Completas, vol. 12 (pp. 159-174). Buenos Aires, Argentina: Amorrortu.

Lacan, J. (1965). El Seminario. Libro 12. Problemas cruciales para el psicoanálisis. (inédito).

Lacan, J. (1999). La dirección de la cura y los principios de su poder. En Escritos 2 (pp. 565-626). Madrid: Siglo veintiuno.

Miller, J. A. (1.992). Dos dimensiones clínicas: síntoma y fantasma. Buenos Aires, Argentina: Manantial 